
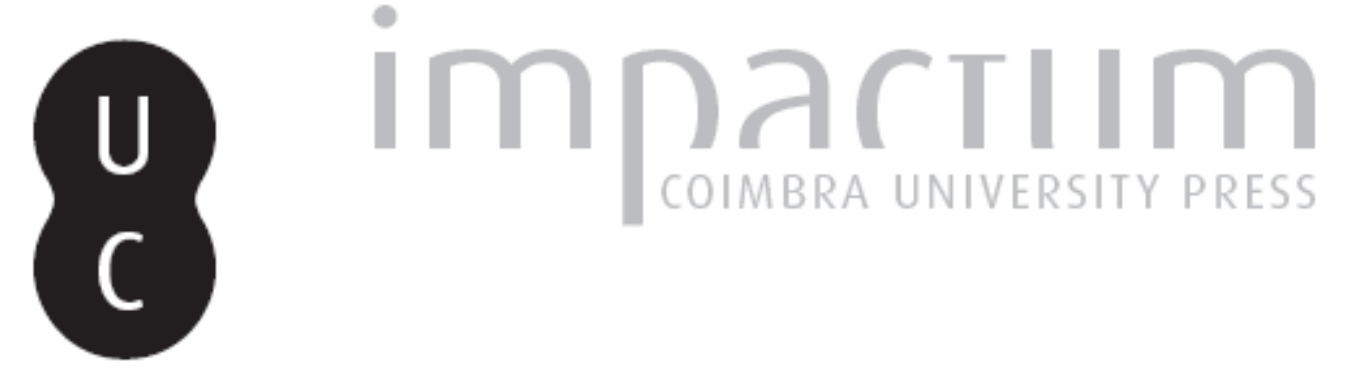

\title{
[Recensão a] GUHA, Amal, Compréhension de textes et représentation de la causalité. La représentation des relations causales dans le cadre d'une sémantique référentialiste en psychologie cognitive
}
Autor(es):
Coxito, Amândio

Publicado por:

Faculdade de Letras da Universidade de Coimbra, Instituto de Estudos Filosóficos

URL persistente:

URI:http://hdl.handle.net/10316.2/33440

DOI:

DOI:http://dx.doi.org/10.14195/0872-0851_43_12

Accessed : $\quad$ 26-Apr-2023 01:03:31

A navegação consulta e descarregamento dos títulos inseridos nas Bibliotecas Digitais UC Digitalis, UC Pombalina e UC Impactum, pressupõem a aceitação plena e sem reservas dos Termos e Condições de Uso destas Bibliotecas Digitais, disponíveis em https://digitalis.uc.pt/pt-pt/termos.

Conforme exposto nos referidos Termos e Condições de Uso, o descarregamento de títulos de acesso restrito requer uma licença válida de autorização devendo o utilizador aceder ao(s) documento(s) a partir de um endereço de IP da instituição detentora da supramencionada licença.

Ao utilizador é apenas permitido o descarregamento para uso pessoal, pelo que o emprego do(s) título(s) descarregado(s) para outro fim, designadamente comercial, carece de autorização do respetivo autor ou editor da obra.

Na medida em que todas as obras da UC Digitalis se encontram protegidas pelo Código do Direito de Autor e Direitos Conexos e demais legislação aplicável, toda a cópia, parcial ou total, deste documento, nos casos em que é legalmente admitida, deverá conter ou fazer-se acompanhar por este aviso.

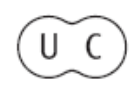




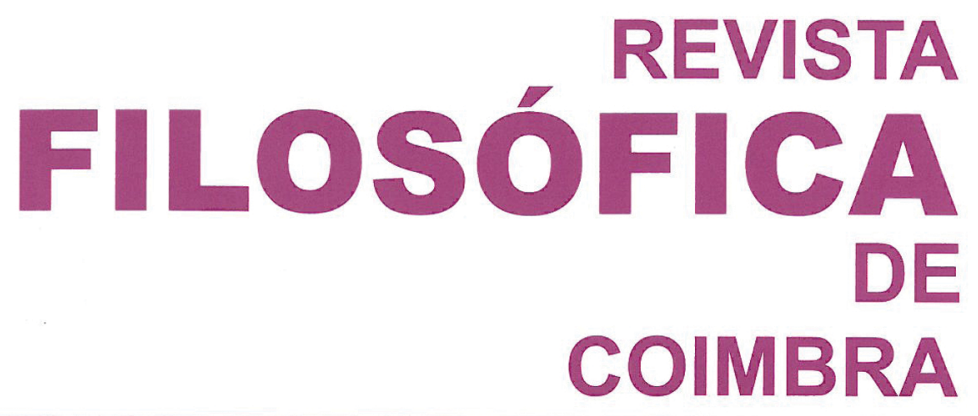

vol. 22 - número 43 - março 2013

vol. 22 - número 43 - março 2013

Fundação Eng. António de Almeida

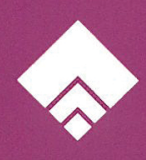


GUHA, Amal, Compréhension de textes et représentation de la causalité. La représentation des relations causales dans le cadre d'une sémantique référentialiste en psychologie cognitive, Éditions universitaires européennes, 2012, 460pp.

Nesta obra de Amal Guha, a compreensão de textos consiste em elaborar uma representação daquilo a que eles se referem. Esta representação é apenas um conjunto de informações. Ela é estruturada e hierarquizada. E o estudo psicológico da compreensão de textos propõe-se caracterizar as propriedades dessa representação. Quanto à "representação das relações" (como consta do subtítulo da obra), a relação de causalidade ocupa um lugar particular não só pela sua natureza, mas também pela sua importância, pois exerce uma função essencial por conferir ao mundo a sua coerência. Em virtude da sua natureza, a relação causal ocupa um lugar particular relativamente a várias problemáticas do campo da compreensão do texto. E no domínio da compreensão do texto narrativo pode comprovar-se a importância da coerência causal. Mas o objectivo principal desta obra consiste sobretudo em estudar a causalidade no âmbito das séries causais relativas a textos explicativos.

A obra está dividida em duas partes (La causalité: définition, caractérisations, compréhension e Étude empirique de la force causale dans les chaînes causales explicatives). No primeiro capítulo (intitulado La causalité: définitions, questions), o autor afirma que é necessário examinar, em primeiro lugar, o problema da causalidade nas coisas, após o que levanta várias questões, nomeadamente: Pode definir-se a causalidade? E como deve caracterizar-se? Ela é um facto objectivo ou psicológico? Seguidamente apresenta as principais teorias sobre a causalidade, referindo-se às de Platão, de David Hume, de Kant e de outros pensadores modernos, nomeadamente Walter Kintsch e Rolph Zwaan. Antes disso, porém, está escrito neste capítulo que a causalidade pode ser entendida em três aspectos: ontológico (ou causalidade nas coisas), psicológico e epistemológico. O primeiro é considerado um dos problemas fundamentais da filosofia desde Platão. Mas na evolução das ideias sobre a causalidade existem sobretudo argumentos metafísicos, que opõem realistas a idealistas. Afirmando o autor da obra que não se propõe realizar uma história de todas as doutrinas sobre a causalidade, expõe, no entanto, desenvolvidamente neste capítulo a posição de David Hume por ser um ponto de referência para a maior parte das produções sobre psicologia, epistemologia e filosofia da causalidade. Com efeito, a crítica de Hume tem um interesse particular, pois ela é a primeira que explicita claramente a articulação entre os aspectos ontológico, epistemológico e psicológico da causalidade. Hume critica a concepção "produtivista" da causalidade, opondo-se à concepção tradicional. De acordo com esta, a causalidade é a produção de algo segundo uma certa lei, ou norma, inerente às próprias coisas ou, por outras palavras, é a transmissão de propriedades de uma coisa a outra segundo certos princípios. Deste modo, a relação causa-efeito, assim entendida, implica uma conexão necessária entre 
duas coisas ou fenómenos. Consequentemente, o efeito está incluído na causa, existindo, portanto, entre ambos uma relação analítica, isto é, uma relação que é descoberta pela análise da natureza dos objectos. Assim, analisando a natureza do fogo, certificamo-nos de que ele tem a propriedade de aquecer os corpos. Hume, porém, critica a ideia de conexão necessária ou a ideia de "poder" e de "eficácia" das causas, dado não existir uma impressão sensível correspondente a essa ideia, quer no domínio da sensibilidade externa, quer no da interna. Apenas se verificam conjunções e sucessões de fenómenos, o que não permite concluir que existam conexões entre eles, pois em si mesmos são isolados. A rejeição por Hume de conexões necessárias (e, portanto, de que elas se hão-de realizar sempre) tem como consequência a impossibilidade de afirmar que as conjunções entre os fenómenos continuarão a verificar-se necessariamente no futuro, dado que desse futuro não temos ainda experiência (logicamente não repugna que essa conjunções não se verifiquem). Mas ainda que não exista uma conexão necessária e objectiva, existe, no entanto, no indivíduo humano a crença na ideia de "conexão necessária" (isto é, de conexão objectiva entre os fenómenos). Acreditamos nessa conexão quando há conjunção constante de fenómenos, a qual tem influência sobre o espírito ou a imaginação, pelo que o aparecimento ou a experiência conjunta de dois objectos ou fenómenos (por exemplo, do fogo e do corpo aquecido) determina o relacionamento das ideias correspondentes. E quando aparece de novo um dos objectos, a respectiva ideia evoca, por associação, a ideia do segundo (não são pois, os objectos ou os fenómenos que estão em relação ou conexão necessária, mas as ideias correspondentes). Portanto, a necessidade causal é algo subjectivo em virtude do hábito. Trata-se de uma explicação psicológica da causalidade. No entanto, há no homem a tendência natural e instintiva para aplicar aos objectos o que é apenas uma conexão mental. Em conclusão, a rejeição da causalidade objectiva ou real em Hume tem como consequência um cepticismo científico (pelo menos segundo muitos intérpretes). Amal Guha resume em duas frases a crítica de Hume à concepção anterior sobre a causalidade: "em primeiro lugar, a causalidade é um facto do entendimento, e o raciocínio ou a observação não nos ensinam coisa alguma sobre a natureza; em segundo lugar, a inferência causal não se fundamenta racionalmente, dado que a sua validade repousa sobre uma crença impossível de demonstrar" (p.29). Sendo assim, a causalidade é um facto eminentemente mental. Depois de Hume, pôs-se a questão de como conciliar o seu cepticismo com o realismo implícito noutros autores de modo a fundamentar o conhecimento das coisas. Esta questão abriu o caminho ao idealismo kantiano, bem como à elaboração no século XIX de critérios lógicos precisos para a prática da ciência empírica. Isto foi codificado por John Stuart Mill e dominou o pensamento epistemológico dos séculos XIX e XX. E Augusto Comte e os positivistas, assim como os lógicos do Círculo de Viena, retomaram a ideia de que a natureza da causalidade não pode ser conhecida. Antes disso, a resposta mais notável à teoria da causalidade de Hume foi dada por Kant. Kant distingue entre 
formas a priori da sensibilidade e formas a priori do entendimento, sendo estas últimas os conceitos puros ou categorias. As categorias são os modos próprios de o espírito humano conceber as coisas, tornando-se, assim, possível fazer juízos sobre elas. Por exemplo, é em virtude da categoria de causalidade que é possível pensar a sucessão dos fenómenos como uma conexão causal. Em função dessa categoria sabemos a priori que todo o fenómeno tem uma causa, isto é, que o universo está estruturado segundo relações causais necessárias, o que significa a superação da doutrina de Hume. Em conclusão, as nossas experiências possíveis do mundo inserem-se num quadro de relações causais, visto que a causalidade é uma estrutura fundamental a priori do entendimento. $\mathrm{O}$ que no mundo real não se insere neste quadro não é para nós inteligível nem acessível. Por isso, o mundo real que nos é acessível é um mundo governado por relações causais.

Foi na segunda metade do século XIX, época do início da psicologia científi$\mathrm{ca}$, que a natureza da causalidade se tornou o centro do debate epistemológico. O objectivo era decidir se a psicologia é uma ciência natural e se pode estabelecer leis causais, associando factos mentais a outros factos mentais, ou a comportamentos. Para emitir uma opinião sobre esta questão é necessário examinar a natureza da interacção entre o espírito e o corpo; mais especificadamente, entre os factos mentais e os factos do domínio da física. Durante o século XX surgiram várias opiniões sobre este assunto, nomeadamente a de Davidson, segundo o qual a causalidade é nomológica, ou seja, a existência de uma relação causal particular implica a existência de uma lei causal (isto significa a afirmação de um determinismo estrito). Por outro lado, segundo Davidson, podem apresentar-se com legitimidade duas hipóteses sobre a natureza da interacção entre os fenómenos mentais e os físicos. A primeira hipótese é o princípio da interacção causal, segundo o qual pelo menos certos estados mentais interagem com fenómenos físicos. A segunda hipótese é o princípio da ausência de organização dos fenómenos, segundo o qual não existem leis deterministas no sentido estrito a partir das quais se pudesse explicar a verdadeira natureza dos fenómenos mentais. A opinião sobre a causalidade de Davidson é compatível com as opiniões de Hume e de Stuart Mill. Para estes filósofos, como pensa Amal Guha, "a causalidade é essencialmente uma lei, isto é, uma síntese da experiência" (p. 33).

Seguidamente, o autor propõe-se discorrer sobre certas questões a que procuraram responder as diferentes teorias sobre a causalidade. Ele refere em primeiro lugar a importância da noção de lei causal, pois sem esta lei não existe relação de causalidade. Por outras palavras, um acontecimento singular para ser considerado causal implica uma lei causal. Esta opinião é sustentada por aqueles que concebem a causalidade como uma síntese da experiência e também pelos racionalistas, segundo os quais a causalidade é observável em ocorrências singulares. Em segundo lugar, Amal Guha faz alusão à multiplicidade das causas, referindo, entre outras, a causa necessária, a causa suficiente e a causa necessária e suficiente. Esta pode ser expressa deste modo: "Se A é uma causa necessária e 
suficiente de B, então A é a causa única de B". Em conformidade com a tradição peripatética, o autor distingue ainda entre a causa primeira e a causa segunda. Esta é toda a causa dependente de outra. E a causa primeira é aquela de que as outras dependem numa série causal, pelo que na natureza ela não está separada do seu efeito.

A respeito do tema "experiência da causalidade", o autor refere que as duas espécies fundamentais de relação causal são, por um lado, o efeito produzido por uma vontade operante e, por outro, a causalidade regida pelas leis físicas da natureza. No primeiro caso, a vontade que realiza o efeito é a vontade humana, ou a divina. A diferença fundamental entre a causalidade em que participa a vontade humana e a causalidade física consiste em que, no caso da vontade humana como causa, se confundem a causa eficiente e a causa final. É por isso necessário pensar de modo diferente as duas espécies de relações causais, a humana e a física, dado que na natureza apenas o ser humano é dirigido pela causa final. $\mathrm{Na}$ verdade, os seres racionais não apenas apreendem o fim como um bem, mas também conhecem os meios adequados para atingi-lo, ordenando para esse efeito os seus actos. O último tema do primeiro capítulo denomina-se "causalidade e discurso", referindo o autor que os objectivos pragmáticos do discurso têm grande importância na apreensão da causa. Aliás, as causas do discurso podem ser consideradas causas "naturais", dizendo respeito não ao nível do conteúdo do discurso, mas ao nível do acto do discurso. E o plano do discurso pode ser de dois modos um referencial de avaliação das causas do mundo a que o discurso se refere. Com efeito, o discurso determina um ponto de vista na descrição dos acontecimentos que definem um contexto.

Amal Guha conclui o primeiro capítulo afirmando que o seu propósito foi essencialmente apresentar os diferentes aspectos da causalidade nas coisas. E também refere que o plano dos actos do discurso tem um lugar importante na própria determinação das causas no mundo.

O segundo capítulo tem por título La relation de causalité dans une aproche multidimensionnelle de la compréhension de textes. Enquanto no primeiro capítulo o autor se propôs apresentar os principais problemas relativos à definição de causalidade com o objectivo de fornecer ao leitor um contexto teórico suficiente para compreender a causalidade, neste capítulo aborda a causalidade relativamente à sua função na compreensão de textos. Compreender um texto é elaborar acerca dele uma representação mental coerente. E Amal Guha propõe-se mostrar que as representações mentais do texto são entidades estruturadas e que existem vários níveis de representação. Ele salienta a representação da situação a que o texto se refere, preferentemente à representação da estrutura formal do texto e do seu conteúdo semântico imediato. Falando de coerência textual, ele afirma que as relações de coerência entre frases realizam a unidade do texto. E existe uma distinção entre coerência e coesão. Em linguística, a coerência é um princípio de conformidade entre os elementos cognitivos activados pelas expressões 
linguísticas presentes num texto e o conhecimento do mundo por parte do leitor. E a coesão é um princípio de unidade semântica de um texto, garantido por um conjunto de mecanismos linguísticos que articulam e sequenciam os diferentes elementos textuais. São estas as características que se deduzem da sequência de frases apresentadas por Amal Guha (p. 69).

A propósito da expressão "representação mental do texto" (p. 71), poderíamos fazer alusão à obra de Van Dijk (Strategies of discourse comprehension), que refere dois níveis de representação, contendo o segundo as ideias principais do texto, hierarquizadas em função da sua importância. As partes seguintes do capítulo referem-se à estrutura dos conhecimentos que possuem coerência (nomeadamente os conhecimentos úteis ao leitor para elaborar as suas representações, os princípios a ter em conta na coerência da representação, as características das relações de coerência no modelo de situação, a importância da coerência do modelo de situação e ainda outras espécies de relação de coerência evidenciadas experimentalmente, por exemplo as emoções e outras características de certas pessoas, como ser vegetariano ou gostar de divertir-se. Amal Guha faz ainda alusão à natureza multidimensional do modelo de situação, bem como à função da causalidade nesse modelo. E também se refere pormenorizadamente ao papel da dimensão causal na compreensão de textos, assim como à coerência causal para que eles possam ser compreendidos. Por último, o autor refere uma experiência na qual alguns participantes num concurso deviam ler um certo número de frases, concluindo ele que o tempo de leitura é tanto menor quanto a força causal é maior; por isso, à medida que a força causal diminui o tempo de leitura aumenta. Isto significa que as experiências realizadas por Amal Guha tinham um objectivo prático, visto que a leitura das frases era seguida de perguntas sobre a compreensão do texto por parte dos participantes no concurso. $\mathrm{O}$ autor conclui que a finalidade deste segundo capítulo foi estudar as noções essenciais e as principais consequências empíricas respeitantes à causalidade num contexto multidimensional da representação mental do texto. Nesta conclusão ele apresenta primeiramente o quadro teórico em que se situam as suas análises. Em segundo lugar, enumera os diferentes aspectos de coerência dos modelos de situação. O modelo de indexação múltipla proposto por Zwaan e seus colaboradores foi a primeira teoria por ele estudada para integrar os diferentes aspectos da coerência. Segundo esta teoria, a coerência do modelo de situação comporta cinco dimensões: o tempo, (por exemplo, Amal Guha refere que numa série de experiências estudou o efeito da introdução de uma ruptura na história), o espaço, os protagonistas, os fins e as causas. E depois de ter situado a causalidade num quadro multidimensional, apresenta os temas do domínio da compreensão dos textos. Os seus resultados empíricos manifestam a função essencial da causalidade na representação do texto, sobretudo do texto narrativo. A verdade é que o autor analisou sobretudo neste capítulo questões relativas ao texto narrativo. 
O terceiro capítulo intitula-se Objectifs de l'approche empirique. Ele tem em vista apresentar a problemática e os métodos do estudo empírico da dimensão causal. Depois de uma introdução às questões em que o autor explica a distância causal mental, enunciam-se os problemas de cada uma delas para determinar o campo do trabalho empírico, tendo em vista o tratamento desses problemas. $\mathrm{O}$ principal objectivo deste capítulo é duplo: descrever segundo dois aspectos complementares a estrutura mental dos conhecimentos correspondentes à relação de causalidade; realizar um estudo da colocação ou disposição de certas categorias de palavras na frase, bem como da função do contexto. Com efeito, a série causal não é um texto "natural"; mas um contexto enriquece-se numa sucessão de frases. E o leitor apoia-se no conjunto de informações que integrou no contexto.

Vários aspectos do conteúdo semântico das frases de um texto variam em função do lugar que ocupam as frases no texto. Por exemplo, a primeira frase de um texto ou de um parágrafo serve muitas vezes para introduzir um tema. Seguidamente, é exposta uma questão relativa à explicação da causalidade por factores situacionais, afirmando-se que esta questão se fundamenta no facto de a relação de causalidade ser uma dimensão da coerência mais complexa que o tempo, o espaço e até os fins (que são todos eles casos particulares da causalidade), sendo por isso necessário examinar profundamente a articulação da causalidade com as outras suas dimensões. Com efeito, além de uma ontologia da causalidade ser difícil de estabelecer e os seus critérios epistemológicos serem complexos, a relação de causalidade não é independente de factores temporais e espaciais. Poderíamos dar como exemplo o facto de a causa nunca resultar da consequência.

Por último, o autor refere-se à causalidade relativa a textos de vulgarização, que ele denomina "explicativos", se forem do domínio da ciência. As outras espécies de textos são as seguintes: os textos expositivos (expor uma explicação causal de um fenómeno é um dos objectivos mais frequentes de um texto), os argumentativos (que justificam ou refutam opiniões com o fim de influenciar o leitor) e os narrativos (que expõem um universo constituído por personagens e eventos reais ou fictícios localizados no tempo e no espaço). Amal Guha conclui afirmando que o seu objectivo foi estudar a topologia e os factores de distância causal a fim de evitar tanto quanto possível o estudo dos factores retóricos e argumentativos, fazendo incidir a sua atenção principalmente sobre a problemática da causalidade, nomeadamente da causalidade factual.

Os capítulos quarto e quinto têm a mesma denominação: Topologie de la distance causale. Mas cada um deles inclui um estudo diferente. $\mathrm{O}$ capítulo quarto tem em vista tratar problemáticas já referidas no capítulo anterior, nomeadamente: topologia da distância causal (que consiste numa investigação da topologia da força causal), distância causal e dinâmica textual (que se refere à função do contexto no discurso), distância causal e inferências (que estuda as distâncias causais intermédias em que o esforço cognitivo associado à elaboração de inferências é maior) e familiaridade e distância causal. Resumindo estes temas, 
o capítulo quarto propõe-se estudar a relação entre a distância causal mental expressa por juízos de plausibilidade. Mas a maior parte das páginas contêm símbolos, gráficos, figuras e a respectiva explicação, o que para um leitor que não seja versado nestes assuntos se tornam difíceis de entender. $\mathrm{O}$ mesmo deve dizer-se do capítulo quinto, cujo objectivo é confirmar e desenvolver os temas do capítulo anterior, referentes sobretudo aos juízos de plausibilidade. Porém, ambos os capítulos permitem estabelecer a importância da plausibilidade enquanto medida da força causal para as séries causais procedentes de textos explicativos.

O capítulo sexto denomina-se Analyse a priori des facteurs descriptifs de la relation causale. $\mathrm{O}$ seu primeiro objectivo consiste em propor um sistema coerente de princípios que permitam descrever a dimensão temporal e a referencial para transformar um texto escrito em linguagem clara num conjunto de sinais, de letras e de números segundo equivalências próprias de um código. Seguidamente o autor analisa a dimensão temporal e a dimensão espacial, referindo-se aos aspectos da continuidade temporal e da espacial, dando exemplos. Desenvolve ainda um tema que ele denomina "descripteurs de la continuité référentielle", após o que faz alusão ao tema "categorizações semânticas da causalidade", no qual se propõe enumerar alguns critérios de classificação da causalidade factual susceptíveis de caracterizar os processos cognitivos, em oposição ao domínio dos conhecimentos específicos. E termina afirmando que se inspirou na psicologia do desenvolvimento e na semântica cognitiva para elaborar alguns critérios semânticos, nomeadamente: natureza da causa e da consequência; características da causa; referentes implícitos na causalidade; possibilidade de interacção com a causa; características da consequência; reciprocidade da relação entre a causa e a consequência; protótipos da causalidade mecânica.

O capítulo sétimo (Prédiction de la plausibilité par des facteurs situationnells et sémantiques) é quase todo ele preenchido (tal como os capítulos quarto e quinto) por símbolos, gráficos e figuras e até em maior quantidade. Podemos, porém, afirmar que este capítulo (e até toda a obra) tem em vista o estudo das propriedades e dos determinantes da força causal, ou distância causal mental, em séries causais resultantes de textos explicativos. E a contribuição de toda a obra para a compreensão da noção de força causal fornece uma base comparativa e os instrumentos para a investigação no domínio da argumentação.

Amândio Coxito 